\title{
Underlying Mechanism of Hypoxic Preconditioning Decreasing Apoptosis Induced by Anoxia in Cultured Hippocampal Neurons
}

\author{
Li-ying Wu Ai-shi Ding Tong Zhao Zi-min Ma Fu-Zhuang Wang Ming Fan \\ Department of Neurobiology, Institute of Basic Medical Sciences, Beijing, PR China
}

\section{Key Words}

Hypoxic preconditioning - B-Cell lymphoma protein-2 • Mitochondrial membrane potential $\cdot$ Hippocampal neurons $\cdot$ Apoptosis

\begin{abstract}
It is known that hypoxic preconditioning (HP, a brief period of sublethal hypoxia) provides neuroprotection against subsequent severe anoxia, but the mechanisms of this increased tolerance have not been fully elucidated. A hypoxic preconditioning model was established by exposing a 4-day hippocampal culture to $1 \% \mathrm{O}_{2}$ for $20 \mathrm{~min} /$ day for 8 days. The preconditioning significantly decreased the number of apoptotic neurons at reoxygenation $24 \mathrm{~h}$ after $4 \mathrm{~h}$ of severe anoxia $\left(0 \% \mathrm{O}_{2}\right)$. Further study demonstrated that the degradation of mitochondrial membrane potential (MMP) was greatly inhibited and the expression of B-cell lymphoma protein-2 (Bcl-2) was increased considerably after severe anoxia in the HP groups. These results indicate that the increased anoxic tolerance, which is induced by HP in cultured hippocampal cells, may be correlated with $\mathrm{Bcl}-2$ overexpression and enhanced stability of MMP, which ultimately reduces apoptosis $24 \mathrm{~h}$ after reoxygenation.
\end{abstract}

\section{KARGER}

Fax +4161306 1234 E-Mail karger@karger.ch www.karger.com

\section{Introduction}

Brief 'preconditioning' hypoxia using an appropriate time interval and mild hypoxia challenge can induce hypoxic/anoxic tolerance. This process is known as 'hypoxic preconditioning' (HP), and was reported for the first time in the central nervous system by Schurr et al. [1]. Since HP is noninvasive and reproducible, it has been used to study the mechanisms which protect the brain from hypoxia-ischemia-induced damage, particularly in newborn rats [2-4]. Many studies have shown that HPinduced increases in B-cell lymphoma protein-1 (Bcl-2), heat shock proteins, superoxide dismutase and nitric oxide, and HP-induced decreases in N-methyl- $D$-aspartate receptors were involved in the signal transduction pathway resulting in hypoxic/anoxic tolerance [5-10]. However, the protective mechanisms induced by HP have not yet been elucidated.

It is well known that the hippocampus is one of the most important subcortical centers involved in spatial navigation, learning and memory, and it is very vulnerable to hypoxia/ischemia [11-13]. Consequently, it is frequently used in various HP models [14-16]. In this study, cultured hippocampal neurons were used to test the protective roles of HP against subsequent severe anoxia. HP with hypoxia for $20 \mathrm{~min} /$ day for 8 days increased neuron 
viability by $11 \%$ after $4 \mathrm{~h}$ of anoxia and $21 \%$ at $24 \mathrm{~h}$ after reoxygenation, as compared to neurons without HP. It was not clear whether HP rescued neurons from necrotic or apoptotic cell death, thus we proceeded with detection of apoptosis.

The mitochondrial membrane potential (MMP) is closely correlated with the occurrence of apoptosis. Some experiments have demonstrated that MMP is decreased during hypoxia/reoxygenation, and it is followed by cytochrome c release, which triggers the activation of caspase9 and caspase-3, and finally apoptosis occurs [17]. It is thus clear that a stable MMP during anoxia would tend to inhibit apoptosis. In the present study, we determined that HP preserved MMP during anoxia in the cultured hippocampal neurons.

Bcl-2 belongs to a family of apoptosis-regulatory proteins, which localizes in the outer mitochondrial membrane and can prevent apoptosis and some forms of cellular necrosis [18-21]. It has been shown that overexpression of Bcl-2 can interfere with mitochondria-controlled apoptotic pathway by blocking the degradation of MMP and the subsequent release of pro-apoptotic molecules [22-25]. Although our previous investigation showed that HP increased the expression of Bcl-2 in hypothalamic neurons, the exact effect of HP on Bcl-2 expression in hippocampal neurons still remained unclear.

\section{Materials and Methods}

\section{Cell Culture}

Neonatal Wistar rats were anesthetized with ethanol and the hippocampi were separated from the brain under sterile conditions. Cells were enzymatically dissociated and seeded in a $35-\mathrm{mm}$ culture dish at a density of $5 \times 10^{5}$ cells $/ \mathrm{cm}^{2}$. The culture medium consisted of 80\% Dulbecco's modified Eagle's medium (Gibco), 10\% heat-inactivated $\left(56^{\circ} \mathrm{C}\right.$ for $30 \mathrm{~min}$ ) horse serum (Hyclone), and $10 \%$ fetal bovine serum (Hyclone). $\mathrm{NaHCO}_{3}(1.5 \mathrm{~g} / \mathrm{l})$ was added to the medium to increase its buffering capacity so that it could be incubated in a gas mixture of $90 \%$ air and $10 \% \mathrm{CO}_{2}$ atmosphere [26]. Cultures were maintained at $36^{\circ} \mathrm{C}$ in the same gas mixture at close to $100 \%$ relative humidity. Non-neuronal cells were eliminated by treatment with arabinosyl cytosine $(5 \mu \mathrm{mol} / \mathrm{l})$ for $24 \mathrm{~h}$ on day 5 in culture. The cell cultures consisting of approximately $85-95 \%$ neurons and $5-15 \%$ glia were confirmed by immunocytochemical staining with antibodies against glial fibrillary acidic protein (astrocyte-specific protein, Sigma).

\section{Hypoxic Preconditioning and Severe Anoxia}

On the 4th day of culture, neurons in the HP group were placed in a $2,000-\mathrm{cm}^{3}$ air-tight chamber, partially submerged in a $42^{\circ} \mathrm{C}$ water bath to maintain a constant thermal environment at $36^{\circ} \mathrm{C}$ ambient temperature. A gas mixture of $1 \% \mathrm{O}_{2} / 10 \% \mathrm{CO}_{2} / 89 \% \mathrm{~N}_{2}$ was delivered into the chamber at a flow rate of $200 \mathrm{ml} / \mathrm{min}$. The neurons were exposed to this for $20 \mathrm{~min}$, and then immediately returned to normoxia conditions. This procedure was repeated for 8 days. Neurons in the control group were cultured in a gas mixture of $90 \%$ air and $10 \% \mathrm{CO}_{2}$ for 12 days. After 12 days, neurons in the 2 groups were exposed to an anoxic gas of $0 \% \mathrm{O}_{2} / 10 \%$ $\mathrm{CO}_{2} / 90 \% \mathrm{~N}_{2}$ for $4 \mathrm{~h}$. Assays were carried out immediately after anoxia and $24 \mathrm{~h}$ after the reoxygenation that followed anoxia, respectively.

\section{Neuron Viability}

Neuron viability was assessed by trypan blue exclusion. Before anoxia, after anoxia and $24 \mathrm{~h}$ after reoxygenation, cell cultures were stained with $0.5 \%$ trypan blue solution for $10 \mathrm{~min}$ at room temperature, fixed with isotonic $0.25 \%$ glutaraldehyde ( $\mathrm{pH} 7.3)$, and rinsed with culture medium. Cells stained with trypan blue were regarded as nonviable. The viable neurons were not stained. To determine neuron viability, at least 750 neurons were counted in each dish.

\section{Terminal Deoxynucleotidyltransferase-Mediated dUTP Nick}

End Labeling (TUNEL) Assay

TUNEL staining was performed to identify apoptotic cells in cultured cell populations. The TUNEL assay was carried out following the protocol suggested by the kit manufacturer (Boehringer Mannheim). Basically, the cell cultures were fixed in a $4 \%$ paraformaldehyde bath for $15 \mathrm{~min}$ at room temperature (RT) and rinsed three times in $0.1 \mathrm{~mol} / 1$ phosphate-buffered saline $(50 \mathrm{mmol} / 1$ of disodium hydrogen phosphate and $200 \mathrm{mmol} / \mathrm{l}$ of dihydrogen phosphate sodium, $\mathrm{pH}$ 7.4). Cells were then digested in $1 \mu \mathrm{g} / \mathrm{ml}$ proteinase K (Sigma) for $10 \mathrm{~min}$ at RT and rinsed three times in $0.1 \mathrm{~mol} / \mathrm{l}$ phosphate-buffered saline (PBS). After inhibition of endogenous peroxidase by 10 -min incubation at RT of $0.3 \% \mathrm{H}_{2} \mathrm{O}_{2}$, cell cultures were rinsed in PBS and incubated for $1 \mathrm{~h}$ at $37^{\circ} \mathrm{C}$ with biotin-dUTP, terminal deoxynucleotidyl transferase (TdT) buffer, TdT enzyme and Bio-16-dUTP. The negative control was prepared in the absence of TdT. After washing in PBS, cell cultures were incubated with $2 \%$ bovine serum albumin (BSA) for $30 \mathrm{~min}$ at $\mathrm{RT}$, rinsed 3 times in PBS and incubated for $30 \mathrm{~min}$ at RT with a streptavidin-biotin-peroxidase complex (ABC kit, Vector Labs). Finally, cells were stained with diaminobenzidine (Sigma) for at least $10 \mathrm{~min}$. The percentage of TUNEL-positive cells was calculated by the ratio of the number of TUNEL-positive cells over the total number of cells.

\section{Flow Cytometric Analyses of Apoptotic Cells}

Cells were collected by mechanical scraping. After centrifugation, the pellet was suspended in cold $70 \%$ ethanol fixing for at least $30 \mathrm{~min}$ at $4^{\circ} \mathrm{C}$, then washed with PBS, and resuspended in $50 \mu \mathrm{l}$ of $100 \mu \mathrm{g} / \mathrm{ml}$ RNase to ensure that only DNA was stained. Finally, the cells were stained with $200 \mu \mathrm{l}$ of propidium iodide (PI, $50 \mu \mathrm{g}$ / $\mathrm{ml}$ ) and analyzed by flow cytometry [27]. Flow cytometric analyses were performed on a Becton Dickinson flow cytometer (FACSalibur). At least 20,000 events were collected for each sample using the Cell Quest software (Becton Dickinson) and the pulse-processing module for doublet discrimination; debris were excluded from the analysis by an appropriate morphological gate of forward scatter vs. side scatter. After exclusion of necrotic debris, the subG $\mathrm{G}_{0}-\mathrm{G}_{1}$ peak was used to quantify apoptosis [28]. 
MMP Assay

MMP was monitored with the fluorescent dye Rhodamine 123 (Rh123, Sigma) [29]. Briefly, cells were incubated with Rh123 for $30 \mathrm{~min}$ (final concentration $5 \mathrm{mg} / \mathrm{l}$ ) at $37^{\circ} \mathrm{C}$. After removal of Rh123 with artificial cerebral spinal fluid (mmol/1: $\mathrm{NaCl} 124, \mathrm{KCl}$ $3.3, \mathrm{KH}_{2} \mathrm{PO}_{4} 1.2, \mathrm{NaHCO}_{3} 26, \mathrm{CaCl}_{2} 2.5, \mathrm{MgSO}_{4} 2.4$, glucose 10), MMP was evaluated immediately using a laser-scanning inverted confocal microscope (MRC 1024, Bio-Rad). Rh123 was excited using $488 \mathrm{~nm}$ of laser line and the emission signal was observed with a combination of a 510-nm dichronic mirror and a 515-nm cutoff filter.

\section{Immunocytochemistry of $\mathrm{Bcl}-2$}

Cultures were fixed with $4 \%$ paraformaldehyde in PBS for $30 \mathrm{~min}$ at RT and incubated with blocking buffer (2\% horse serum, $1 \%$ BSA, and $0.1 \%$ Triton X-100 in PBS, pH 7.4.). Primary antibody (rabbit polyclonal anti-mouse Bcl-2, 1:1,000, Santa Cruz) was added at $4{ }^{\circ} \mathrm{C}$ overnight, then the cultures were incubated with biotinylated goat anti-rabbit IgG secondary antibody (1:1,000, Santa Cruz) for $1 \mathrm{~h}$ at RT, and placed in avidin-peroxidase conjugate (Vector) solution for $1 \mathrm{~h}$. The horseradish peroxidase reaction was detected with $0.02 \%$ diaminobenzidine, $0.68 \%$ ammonium nickel sulfate and $0.03 \% \mathrm{H}_{2} \mathrm{O}_{2}$. Processing was stopped with $\mathrm{H}_{2} \mathrm{O}$. An imaging analyzer (QUANTIMET 970, Cambridge Instruments Company) was used to determine levels of Bcl-2 expression.

\section{Statistical Analysis}

All values are shown as mean $\pm \mathrm{SD}$. The differences in values between the HP group and the control group were assessed by unpaired two-tailed Student's t test. Differences were considered to be statistically significant at a level of $\mathrm{p}<0.05$.

\section{Results}

\section{Effect of HP on Neuron Viability}

Before severe anoxia, there was no difference in the neuron survival rate between the HP group and the control group (fig. 1). This suggested that HP per se had no obvious effects on neuron viability. When cultured neurons were subjected to 4-hour hypoxia, neuronal death was observed, especially $24 \mathrm{~h}$ after reoxygenation. However, the neuron survival rate of the HP group was significantly higher than that of the control group after anoxia and $24 \mathrm{~h}$ of reoxygenation, respectively. This result demonstrated that neurons exposed to HP were more resistant to anoxia-induced injury.

\section{HP Decreases Apoptotic Cell Death after 24 h of}

\section{Reoxygenation}

In order to determine whether HP protected neurons from apoptosis or necrosis, we examined cellular morphology and identified apoptotic cells using two different methods. In the TUNEL assay, the round black cells were TUNEL-positive (fig. 2a). The TUNEL-positive cells dis-

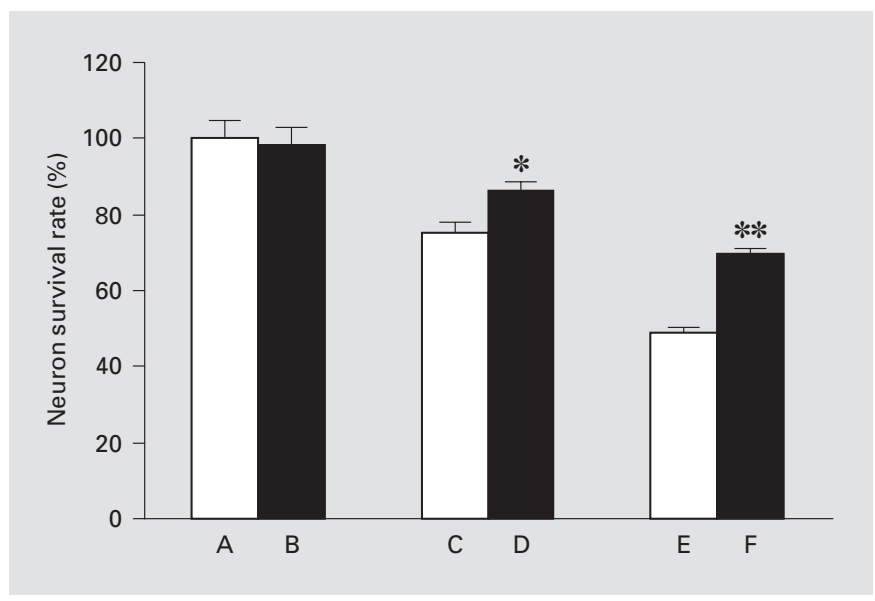

Fig. 1. Effect of HP on neuron viability. Neuron viability was tested by trypan blue exclusion. Before anoxia $(\mathrm{A}=$ control group; $\mathrm{B}=$ HP group), after anoxia ( $\mathrm{C}=$ control group; $\mathrm{D}=\mathrm{HP}$ group) and $24 \mathrm{~h}$ after reoxygenation ( $\mathrm{E}=$ control group; $\mathrm{F}=\mathrm{HP}$ group), cell cultures in the 2 groups were stained with trypan blue solution. Cells stained with trypan blue were regarded as nonviable. The value of the number of surviving neurons in the control group before anoxia was taken as $100 \%$. The neuron survival rate in the HP group was compared with the control value at different time points. At least 4,500 neurons were counted in each experiment. Data are expressed in mean \pm SD of duplicate measurements from 3 independent experiments. ${ }^{*} \mathrm{p}<0.05 ; * * \mathrm{p}<0.01$ compared with the control.

played the morphological characteristics of apoptosis, which included cell shrinkage, rounding, and pyknotic nucleus. Figure $2 \mathrm{~b}$ shows the percentage of TUNEL-positive cells at different time points. A few TUNEL-positive cells were seen in the 2 groups before anoxia. The number of TUNEL-positive cells was slightly increased after anoxia and was maximal $24 \mathrm{~h}$ after reoxygenation in each group. After anoxia, there were $12.92 \%$ TUNEL-positive cells in the HP group and $14.62 \%$ in the control group ( $p>0.05$ ). By $24 \mathrm{~h}$ after reoxygenation, TUNEL-positive cells reached $27.56 \%$ in the HP group and $43.57 \%$ in the control group $(\mathrm{p}<0.01)$. This demonstrated that HP decreased apoptosis significantly $24 \mathrm{~h}$ after reoxygenation. In order to verify the TUNEL assay, the percentage of apoptotic cells was further tested using flow cytometry by PI staining (fig. 2c). As seen in figure $2 \mathrm{c}$, only a small proportion of cells had subG $G_{0}-G_{1}$ DNA content, which is representative of cells with decreased PI staining and is an indicator of DNA fragmentation associated with apoptotic cell death. The results were very similar to the TUNEL assay and confirmed the effect of HP on apoptosis. 

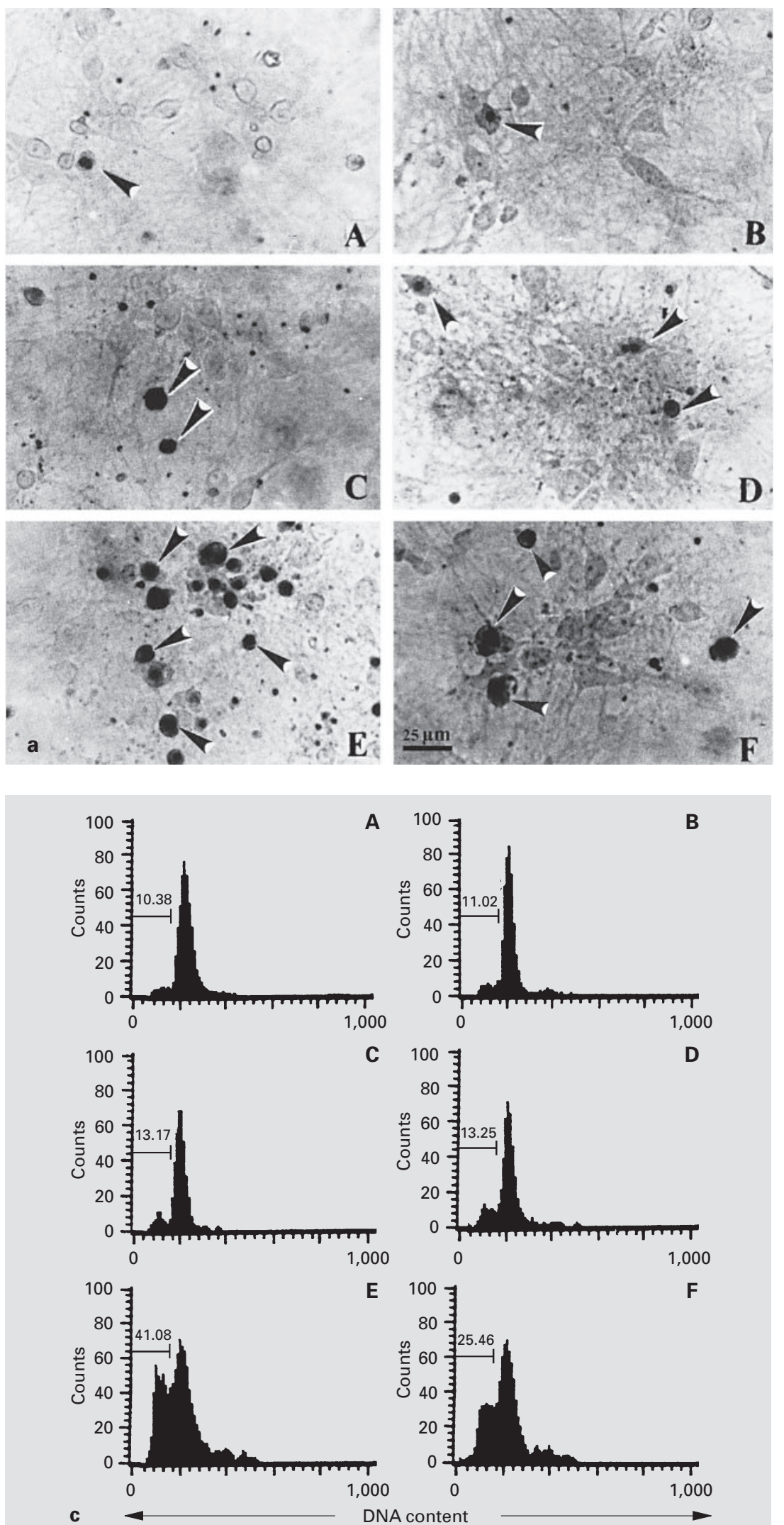

E 100

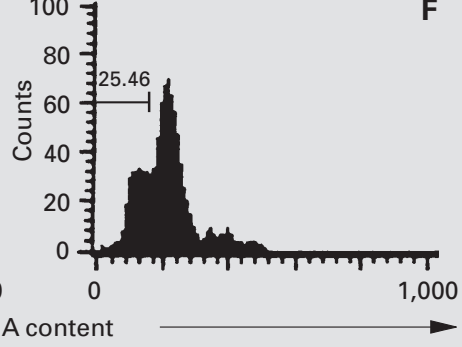

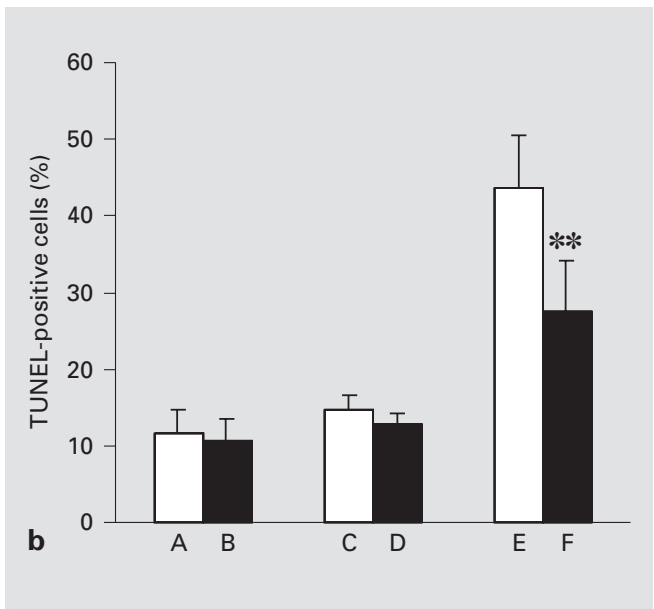

Fig. 2. Effect of HP on apoptosis. a, b TUNEL staining and the statistical graph are shown, respectively. a A, C and E show TUNEL staining in the control group before anoxia, after anoxia and $24 \mathrm{~h}$ after reoxygenation, respectively, in cultured hippocampal neurons. B, D and F show TUNEL staining in the HP group before anoxia, after anoxia and $24 \mathrm{~h}$ after reoxygenation, respectively. Arrows indicate the TUNEL-positive cells. b Columns show a percentage of TUNEL-positive cells relative to the total number of cells. The treatment conditions of $\mathrm{A}-\mathrm{F}$ are same as those of $\mathrm{A}-\mathrm{F}$ in a. Data are mean $\pm \mathrm{SD}$ of duplicate measurements from 3 separate experiments. ${ }^{* *} \mathrm{p}<0.01$ compared with the control. c Flow cytometric analysis of apoptotic cells using PI staining. Apoptotic cells with DNA fragmentation were identified by the PI technique and estimated by calculating the number of subdiploid cells in the cell cycle histogram. The cells with subdiploid DNA content represent the fraction undergoing apoptotic DNA degradation. A, C and $\mathrm{E}$ show flow cytometric analysis of the DNA fragment in the control group before anoxia, after anoxia and $24 \mathrm{~h}$ after reoxygenation, respectively. $\mathrm{B}, \mathrm{D}$ and $\mathrm{F}$ show flow cytometric analysis of the DNA fragment in the HP group before anoxia, after anoxia and $24 \mathrm{~h}$ after reoxygenation, respectively. The number above each bar refers to the percentage of apoptotic cells. Results are representative of 3 separate experiments. 


\section{HP Inhibits Anoxia-Induced Decrease in MMP}

The decrease in MMP can induce the occurrence of apoptosis [30-33]. In order to detect the dynamic changes of MMP during anoxia, a laser-scanning confocal microscope was used to monitor the real-time changes of incorporated Rh123 fluorescence intensity. After anoxia, the fluorescence intensity rapidly attenuated with time in the control group. In contrast, fluorescence intensity gradually attenuated in the HP group (fig. 3). In the initial 2 min of anoxia, the fluorescence intensity decreased $57.23 \pm 0.058 \%$ in the control group and $17.74 \pm 0.086 \%$ in the HP group $(\mathrm{p}<0.01)$. By the end of anoxia, the fluorescence intensity decreased $93.54 \pm 0.047 \%$ in the control group and $49.59 \pm 0.122 \%$ in the HP group $(\mathrm{p}<$ $0.01)$. These data indicate that HP can substantially inhibit the loss of MMP induced by anoxia.

\section{Effect of HP on Bcl-2 Expression}

$\mathrm{Bcl}-2$ protein is primarily localized in the outer mitochondrial membrane, and the overexpression of Bcl-2 can prevent the degradation of MMP [34-36]. Immunocytochemistry was used to determine the effect of HP on expression of $\mathrm{Bcl}-2$. Figure $4 \mathrm{a}$ shows the expression of $\mathrm{Bcl}-2$ detected by immunocytochemical staining at different time points. The expression level of Bcl-2 was assessed by an imaging analyzer (fig. 4b). After anoxia, Bcl-2 level was significantly higher in the HP group than that in the control group $(0.57 \pm 0.13$ vs. $0.36 \pm 0.08, \mathrm{p}<0.01)$. This suggests that HP induces the overexpression of $\mathrm{Bcl}-2$. $24 \mathrm{~h}$ after reoxygenation, there was no significant difference in Bcl-2 level between the 2 groups.

\section{Discussion}

This study evaluated the effects of HP on anoxic tolerance, the pattern of apoptotic degeneration and its related mechanisms after anoxia and $24 \mathrm{~h}$ of reoxygenation in hippocampal cultures. Neuron survival assays demonstrate that HP can protect hippocampal neurons from anoxia-induced cell death. To determine whether HP protected neurons from apoptotic or necrotic cell death, we subsequently examined cellular morphology and labeled the cells to detect apoptosis. Using two apoptosis detection methods, we confirm that anoxia alone does not induce obvious changes in cell apoptosis. In contrast, substantial apoptosis occurs $24 \mathrm{~h}$ after reoxygenation and HP significantly decreases the occurrence of apoptosis in this model. After anoxia there was no obvious difference in the percentage of TUNEL-positive cells between the 2

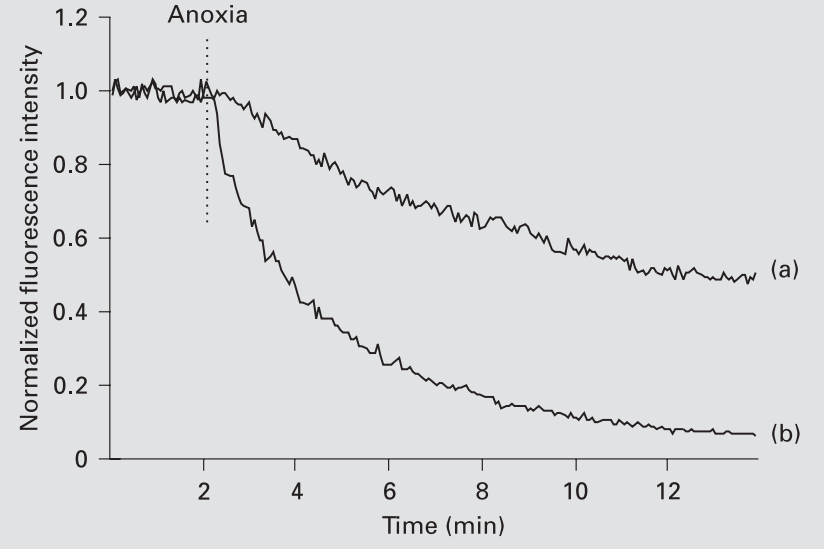

Fig. 3. Dynamic changes of MMP during anoxia. Cells were positively stained with Rh123 followed by confocal microscope scanning to monitor the dynamic changes in MMP. MMP was assessed by the extent of retention of Rh123. A decrease in MMP is shown as a decrease in the fluorescence intensity of Rh123 after exposure to severe anoxia. A rapid decrease in MMP occurs in the control group (b) after anoxia, whereas the decrease in MMP in the HP group (a) is diminished. Each trace represents mitochondrial fluorescence intensity normalized to the initial baseline value. Data represent mean values of 63-81 neurons from 3 separate experiments.

groups. Based on our apoptotic labeling study and the cellular morphology, we suppose that necrosis rather than apoptosis is the main pattern of cell death immediately after anoxia and HP may mainly rescue neurons from necrotic cell death. However, $24 \mathrm{~h}$ after reoxygenation, apoptosis rather than necrosis is the main pattern of cell death and HP may mainly rescue neurons from apoptotic cell death. Therefore, we conclude that HP protects hippocampal neurons from necrosis after severe anoxia and apoptosis $24 \mathrm{~h}$ after reoxygenation.

It has been reported $[17,37,38]$ that loss of MMP during hypoxia/reoxygenation is closely correlated with the occurrence of apoptosis. Hypoxia/reoxygenation induces the degradation of MMP and subsequent cytochrome $\mathrm{c}$ (a critical factor in the initiation of cell death pathways originating from the mitochondrion) release. Cytoplasmic cytochrome $\mathrm{c}$ forms a complex with Apaf-1, which triggers the proteolytic activation of caspase-9. The activated caspase- 9 in turn activates caspase- 3 and thus apoptosis is induced. In this study, in order to evaluate the effects of HP on MMP in cultured hippocampal neurons, we used the cationic and lipophilic dye Rh123 that permeates into the negatively charge mitochondria and therefore reflects the MMP to monitor the real-time 


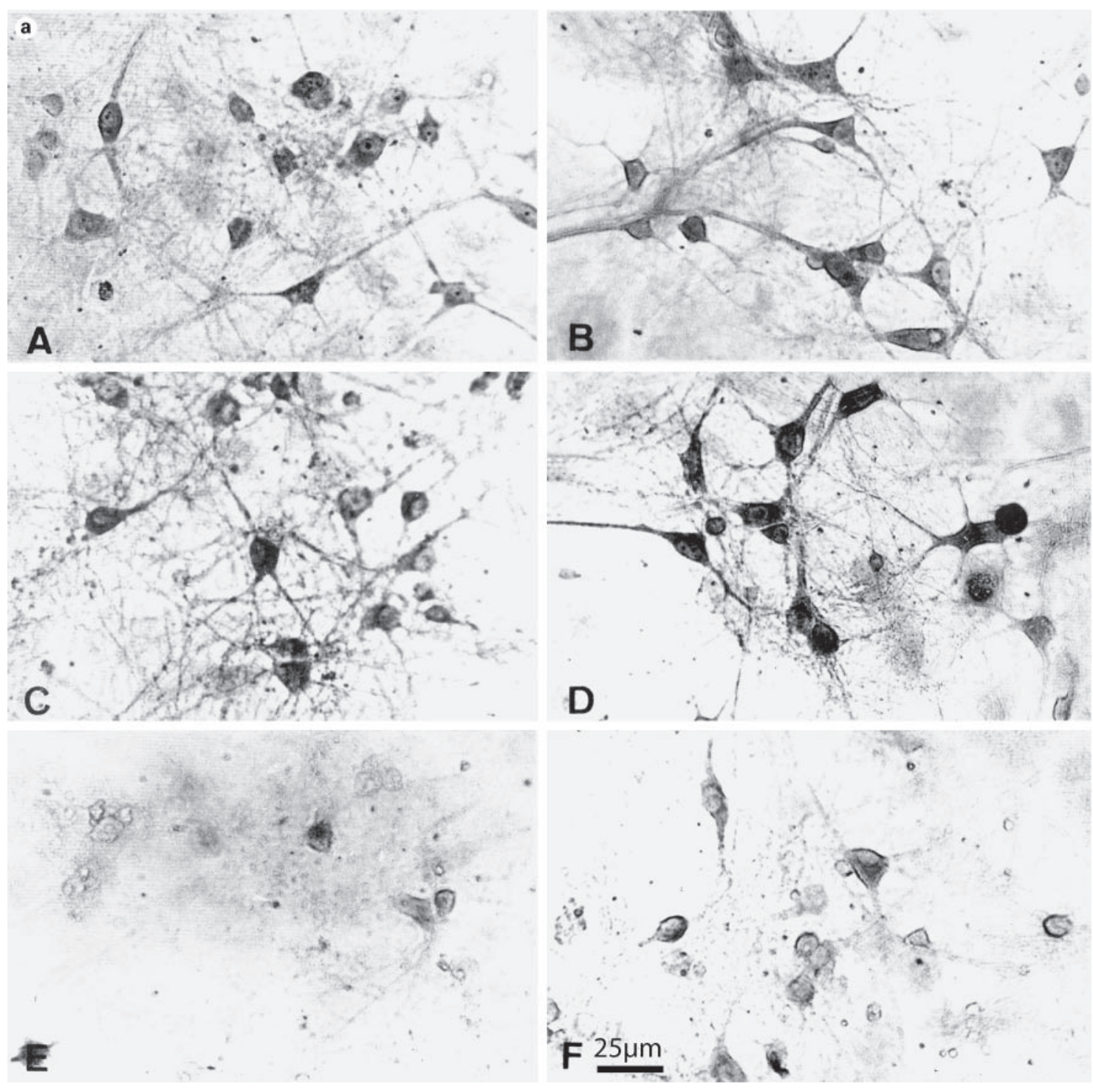

Fig. 4. Effect of $\mathrm{HP}$ on $\mathrm{Bcl}-2$ expression. a, b Immunocytochemical staining of Bcl-2 and its statistical graph respectively. a A, C and $\mathrm{E}$ show the Bcl-2 staining in the control group before anoxia, after anoxia and $24 \mathrm{~h}$ after reoxygenation, respectively, in cultured hippocampal neurons. B, D and $\mathrm{E}$ show the Bcl-2 staining in the HP group before anoxia, after anoxia and $24 \mathrm{~h}$ after reoxygenation, respectively. b Columns show the mean optical density of Bcl-2 staining. The value of the mean optical density represents the level of $\mathrm{Bcl}-2$ expression. The treatment conditions of $\mathrm{A}-\mathrm{F}$ are same as those of $\mathrm{A}-\mathrm{F}$ in $\mathbf{a}$. Data are mean $\pm \mathrm{SD}$ of duplicate measurements from 3 separate experiments. ${ }^{* *} \mathrm{p}<0.01$ compared with the control.

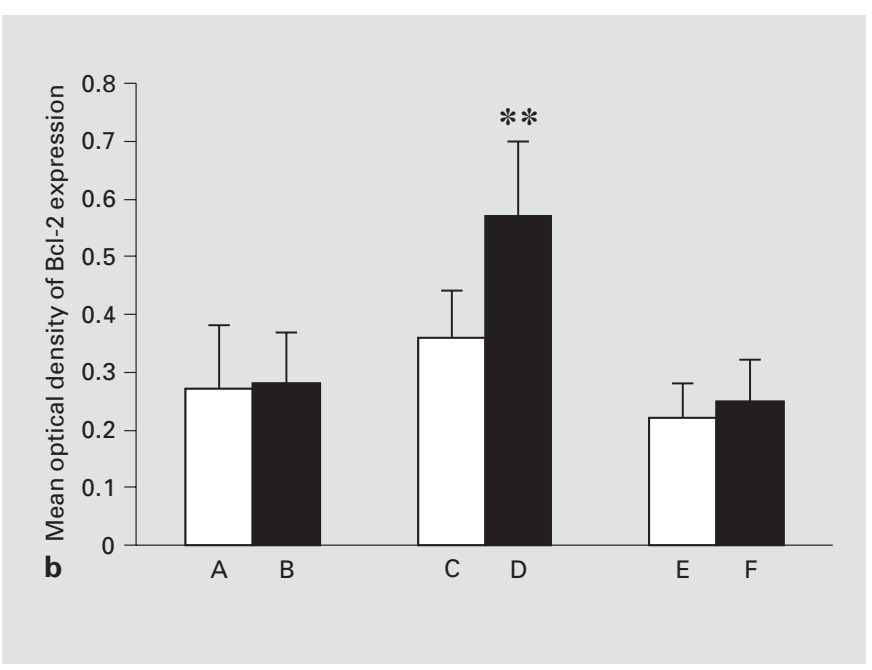


changes in MMP during anoxia. The result shows that MMP drops in the 2 groups during anoxia, while MMP in the HP group is maintained at a higher level as compared to the control group. This indicates that HP can inhibit the breakdown of MMP that is induced by anoxia to some extent. When combined with the result of apoptosis labeling, this result suggests that the maintenance of MMP by HP after anoxia contributes to the reduction in apoptosis observed $24 \mathrm{~h}$ after reoxygenation.

In order to investigate the possible mechanism for HP's maintenance of the MMP, the expression of Bcl-2 in cultured hippocampal neurons was further examined in the present study. Bcl-2 is one of the most important anti-apoptotic members of the Bcl-2 protein family, which incorporates into the outer mitochondrial membrane and can prevent apoptosis as well as cellular necrosis [19-22]. The anti-apoptotic characteristics of Bcl-2 are due to its overriding protective role in various types of injury by preserving mitochondrial structure and function [34, 39, 40]. MMP reflects mitochondrial biological function. Meanwhile, it has been shown that the degradation of MMP induced by a variety of stimuli can be prevented by overexpression of Bcl-2 [19, 34-36, 41]. Therefore it is necessary to detect the expression of $\mathrm{Bcl}-2$ in cultured hippocampal neurons. The result shows that Bcl2 expression increased after severe anoxia and decreased $24 \mathrm{~h}$ after reoxygenation. This indicates that the increase in Bcl-2 expression induced by anoxia is transient. After anoxia, Bcl-2 expression was significantly higher in the
HP group than the control group, and there was no significant difference between the 2 groups $24 \mathrm{~h}$ after reoxygenation. This result reveals that HP induces the overexpression of Bcl-2 after anoxia and does not inhibit the decrease in $\mathrm{Bcl}-2$ expression after reoxygenation. This suggests that the higher level of Bcl-2 in the HP group maintains a higher level of MMP during anoxia. As for the reduction of apoptosis in the HP group $24 \mathrm{~h}$ after reoxygenation, we presume that the relative stability of MMP inhibits the release of apoptotic proteins and the depletion of ATP, and ultimately reduces the rate of necrosis after anoxia and apoptosis after reoxygenation. In addition, it is possible that Bcl-2 overexpression after anoxia triggers other anti-apoptotic signal pathways independent of MMP, which result in the reduction in apoptosis after reoxygenation.

In conclusion, HP can enhance anoxic tolerance and decrease apoptosis induced by anoxia in cultured hippocampal neurons. The underlying mechanism presumably involves overexpression of $\mathrm{Bcl}-2$ and maintenance of MMP.

\section{Acknowledgements}

We are very grateful to Dr. Laura K. Cole (NIH Stem Cell Task Force, USA) and Dr. Chen Wang (Applied Biosystems, Inc., USA) for their stylistic help. The study was supported by a key grant (30393130) from the National Nature Science Foundation of China.

\section{References}

1 Schurr A, Reid KH, Tseng MT, West C, Rigor BM: Adaptation of adult brain tissue to anoxia and hypoxia in vitro. Brain Res 1986;374:244248.

2 Cantagrel S, Krier C, Ducrocq S, Bodard S, Payen V, Laugier J, Guilloteau D, Chalon S: Hypoxic preconditioning reduces apoptosis in a rat model of immature brain hypoxia-ischaemia. Neurosci Lett 2003;347:106-110.

- 3 Jones NM, Bergeron M: Hypoxic preconditioning induces changes in HIF-1 target genes in neonatal rat brain. $\mathrm{J}$ Cereb Blood Flow Metab 2001;21:1105-1114.

-4 Bergeron M, Gidday JM, Yu AY, Semenza GL, Ferriero DM, Sharp FR: Role of hypoxiainducible factor- 1 in hypoxia-induced ischemic tolerance in neonatal rat brain. Ann Neurol 2000;48:285-296.
-5 Garnier P, Demougeot C, Bertrand N, PrigentTessier A, Marie C, Beley A: Stress response to hypoxia in gerbil brain: HO-1 and Mn SOD expression and glial activation. Brain Res 2001;893:301-309.

-6 Duan C, Yan F, Song X, Lu GW: Changes of superoxide dismutase, glutathione peroxidase and lipid peroxides in the brain of mice preconditioned by hypoxia. Biol Signals Recept 1999:8:256-260.

7 Bossenmeyer PC, Daval JL: Prevention from hypoxia-induced apoptosis by pre-conditioning: A mechanistic approach in cultured neurons from fetal rat forebrain. Brain Res Mol Brain Res 1998;58:237-239.

-8 Valentim LM, Rodnight R, Geyer AB, Horn AP, Tavares A, Cimarosti H, Netto CA, Salbego CG: Changes in heat shock protein 27 phosphorylation and immunocontent in response to preconditioning to oxygen and glucose deprivation in organotypic hippocampal cultures. Neuroscience 2003;118:379-386.
-9 Gidday JM, Shah AR, Maceren RG, Wang Q, Pelligrino DA, Holtzman DM, Park TS: Nitric oxide mediates cerebral ischemic tolerance in a neonatal rat model of hypoxic preconditioning. J Cereb Blood Flow Metab 1999;19:331340.

10 Xie J, Lu G, Hou Y: Role of excitatory amino acids in hypoxic preconditioning. Biol Signals Recept 1999;8:267-274.

11 Matsuoka Y, Kitamura Y, Fukunaga R, Shimohama S, Nabeshima T, Tooyama I, Kimura $\mathrm{H}$, Taniguchi $\mathrm{T}$ : In vivo hypoxia-induced neuronal damage in dentate gyrus of rat hippocampus: Changes in NMDA receptors and the effect of MK-801. Neurochem Int 1997;30: 533-542.

-12 Yamaoka Y, Shimohama S, Kimura J, Fukunaga $R$, Taniguchi $T$ : Neuronal damage in the rat hippocampus induced by in vivo hypoxia. Exp Toxicol Pathol 1993;45:205-209. 
13 Volpe BT, Pulsinelli WA, Tribuna J, Davis HP: Behavioral performance of rats following transient forebrain ischemia. Stroke 1984;15: 558-562.

14 Wang X, Deng J, Boyle DW, Zhong J, Lee WH: Potential role of IGF-I in hypoxia tolerance using a rat hypoxic-ischemic model: activation of hypoxia-inducible factor 1alpha. Pediatr Res 2004;55:385-394.

-15 Ota A, Ikeda T, Abe K, Sameshima H, Xia XY, Xia YX, Ikenoue T: Hypoxic-ischemic tolerance phenomenon observed in neonatal rat brain. Am J Obstet Gynecol 1998;179:10751078.

>16 Gidday JM, Fitzgibbons JC, Shah AR, Park TS: Neuroprotection from ischemic brain injury by hypoxic preconditioning in the neonatal rat. Neurosci Lett 1994;168:221-224.

17 Reichert SA, Kim-Han JS, Dugan LL: The mitochondrial permeability transition pore and nitric oxide synthase mediate early mitochondrial depolarization in astrocytes during oxygen-glucose deprivation. J Neurosci 2001;21: 6608-6616.

- 18 Rosenthal DS, Simbulan-Rosenthal CM, Liu WF, Stoica BA, Smulson ME: Mechanisms of JP-8 jet fuel cell toxicity. II. Induction of necrosis in skin fibroblasts and keratinocytes and modulation of levels of Bcl-2 family members. Toxicol Appl Pharmacol 2001;171:107-116.

-19 Shimizu S, Eguchi Y, Kamiike W, Funahashi Y, Mignon A, Lacronique V, Matsuda H, Tsujimoto Y: Bcl-2 prevents apoptotic mitochondrial dysfunction by regulating proton flux. Proc Natl Acad Sci USA 1998;95:1455-1459.

20 Tsujimoto Y, Shimizu S, Eguchi Y, Kamiike W, Matsuda H: Bcl-2 and Bcl-xL block apoptosis as well as necrosis: Possible involvement of common mediators in apoptotic and necrotic signal transduction pathways. Leukemia 1997;11(suppl 3):380-382.

-21 Howard S, Bottino C, Brooke S, Cheng E, Giffard RG, Sapolsky R: Neuroprotective effects of bcl-2 overexpression in hippocampal cultures: Interactions with pathways of oxidative damage. J Neurochem 2002;83:914-923.

22 Gabriel B, Sureau F, Casselyn M, Teissie J, Petit PX: Retroactive pathway involving mitochondria in electroloaded cytochrome c-induced apoptosis. Protective properties of $\mathrm{Bcl}-2$ and Bcl-XL. Exp Cell Res 2003;289:195-210.
23 Akao Y, Maruyama W, Shimizu S, Yi H, Nakagawa Y, Shamoto-Nagai M, Youdim MB Tsujimoto Y, Naoi M: Mitochondrial permeability transition mediates apoptosis induced by $\mathrm{N}$-methyl(R)salsolinol, an endogenous neurotoxin, and is inhibited by $\mathrm{Bcl}-2$ and rasagiline, N-propargyl-1(R)-aminoindan. J Neurochem 2002;82:913-923.

-24 van der Kolk LE, Evers LM, Omene C, Lens SM, Lederman S, van Lier RA, van Oers MH, Eldering E: CD20-induced B cell death can bypass mitochondria and caspase activation. Leukemia 2002;16:1735-1744.

-25 Thomas WD, Zhang XD, Franco AV, Nguyen T, Hersey P: TNF-related apoptosis-inducing ligand-induced apoptosis of melanoma is associated with changes in mitochondrial membrane potential and perinuclear clustering of mitochondria. J Immunol 2000;165:56125620.

26 Ransom BR, Neale E, Henkart M, Bullock PN, Nelson PG: Mouse spinal cord in cell culture. 1. Morphology and intrinsic neuronal electrophysiologic properties. J Neurophysiol 1977; 40:1132-1150.

27 Hamel W, Dazin P, Israel MA: Adaptation of a simple flow cytometric assay to identify different stages during apoptosis. Cytometry 1996;25:173-181.

28 Ghoneum M, Gollapudi S. Modified arabinoxylan rice bran (MGN-3/Biobran) sensitizes human $\mathrm{T}$ cell leukemia cells to death receptor (CD95)-induced apoptosis. Cancer Lett 2003 201:41-49.

29 Ding WX, Shen HM, Shen Y, Zhu HG, Ong $\mathrm{CN}$ : Microcystic cyanobacteria causes mitochondrial membrane potential alteration and reactive oxygen species formation in primary cultured rat hepatocytes. Environ Health Perspect 1998;106:409-413.

30 Teshima Y, Akao M, Li RA, Chong TH, Baumgartner WA, Johnston MV, Marban E: Mitochondrial ATP-sensitive potassium channel activation protects cerebellar granule neurons from apoptosis induced by oxidative stress. Stroke 2003:34:1796-1802.

31 Jones DC, Prabhakaran K, Li L, Gunasekar PG, Shou Y, Borowitz JL, Isom GE: Cyanide enhancement of dopamine-induced apoptosis in mesencephalic cells involves mitochondrial dysfunction and oxidative stress. Neurotoxicology 2003;24:333-342.
32 Prabhakaran K, Li L, Borowitz JL, Isom GE: Cyanide induces different modes of death in cortical and mesencephalon cells. J Pharmacol Exp Ther 2002;303:510-519.

-33 Budd SL, Tenneti L, Lishnak T, Lipton SA: Mitochondrial and extramitochondrial apoptotic signaling pathways in cerebrocortical neurons. Proc Natl Acad Sci USA 2000;97:61616166.

-34 Gabriel B, Sureau F, Casselyn M, Teissie J, Petit PX: Retroactive pathway involving mitochondria in electroloaded cytochrome c-induced apoptosis. Protective properties of Bcl-2 and Bcl-XL. Exp Cell Res 2003;289:195-210.

35 Haraguchi M, Torii S, Matsuzawa S, Xie Z, Kitada S, Krajewski S, Yoshida H, Mak TW, Reed JC: Apoptotic protease activating factor 1 (Apaf-1)-independent cell death suppression by Bcl-2. J Exp Med 2000;191:1709-1720.

>36 Gajate C, Santos-Beneit AM, Macho A, Lazaro M, Hernandez-De Rojas A, Modolell M, Munoz E, Mollinedo F: Involvement of mitochondria and caspase-3 in ET-18-OCH(3)-induced apoptosis of human leukemic cells. Int J Cancer 2000;86:208-218.

37 Xu M, Wang Y, Ayub A, Ashraf M: Mitochondrial K(ATP) channel activation reduces anoxic injury by restoring mitochondrial membrane potential. Am J Physiol Heart Circ Physiol 2001;281:H1295-H1303.

38 Gurevich RM, Regula KM, Kirshenbaum LA: Serpin protein CrmA suppresses hypoxia-mediated apoptosis of ventricular myocytes. Circulation 2001;103:1984-1991.

39 Dispersyn G, Nuydens R, Connors R, Borgers $\mathrm{M}$, Geerts $\mathrm{H}$. Bcl-2 protects against FCCP-induced apoptosis and mitochondrial membrane potential depolarization in PC12 cells. Biochim Biophys Acta 1999;1428:357-371.

40 Guenal I, Sidoti-de Fraisse C, Gaumer S, Mignotte B: Bcl-2 and Hsp27 act at different levels to suppress programmed cell death. Oncogene 1997; 15:347-360

41 Saitoh Y, Ouchida R, Miwa N: Bcl-2 prevents hypoxia/reoxygenation-induced cell death through suppressed generation of reactive oxygen species and upregulation of Bcl-2 proteins. J Cell Biochem 2003;90:914-924. 